The Journal of Black Psychology

February 1983, Vol. 9, No. 2, Pp. 43-56

\title{
Delayed Gratification in Blacks: A Critical Review
}

\author{
W. Curtis Banks \\ and \\ Gregory V. McQuater \\ Social Learning Laboratory \\ Educational Testing Service \\ Jenise A. Ross \\ Institute for Urban Affairs and Research \\ Wanda E. Ward \\ University of Oklahoma
}

\begin{abstract}
Research on the delay of gratification in Blacks was critically reviewed. The methodology typically employed to investigate this construct involves of fering the individual a choice of obtaining either a small, immediate reward or a large, delayed reward. Contrary to previous reports, it is argued here that the evidence divides published studies into those demonstrating overall patterns of nonpreference for delayed versus immediate rewards and those demonstrating overall or partial patterns of preference for delayed rewards among Blacks. Little empirical evidence is provided in the literature of a tendency for Blacks to prefer immediate gratification, or of the relationship of such behavior to other personality characteristics.
\end{abstract}

W. Curtis Banks, Social Learning Laboratory, Educational Testing Service, Princeton, New Jersey 08541 .

Gregory V. McQuater, Department of Human Development and Family Studies, Cornell University, Ithaca, New York 14850.

Jenise A. Ross, Howard University, 2900 Van Ness Street, N.W., Washington, D.C. 20008.

Wanda E. Ward, University of Oklahoma at Norman, Norman, Oklahoma 73069. 
The delay of gratification has been conceptualized as the ability to forego immediate opportunities to satisfy impulses in favor of alternative opportunites that are more remote in time, but often of greater objective value. As such, the ability is one that is believed to distinguish those individuals who succeed and prosper by hard work, thrift, and self-control from those who are susceptible to the temptations of short-term gains and impulsivity. This conceptualization has lent itself to an analysis of class differences in sociopsychological functioning (Davis \& Dollard, 1940; Drake \& Clayton, 1945; Schneider \& Lysgaard, 1953), of cultural differences that distinguish national groups (Mischel, 1961b), and of race differences in personality characteristics (Lessing, 1969; Mischel, 1958; Price-Williams \& Ramirez, 1972; Strickland, 1972).

Davis and Dollard (1940) and Schneider and Lysgaard (1953) argued that the lower class is characterized by "minimum pursuit of education," "low aspirations," a "readiness to engage in physical violence," and "free sexual gratification (as through intercourse)" (p. 143). In contrast, they described the middle class as characterized by a "deferred gratification pattern" of postponed intercourse, delayed economic independence (from parents), and thrift, all of which contribute to their relative achievement, economic success, and social responsibility.

Similarly, a number of more recent studies have contributed to an empirical validation of Drake and Cayton's (1945) and Davis and Dollard's (1940) impressionistic observations about the inability to delay gratification among Blacks. Experimental research has been aimed at establishing the relationship of immediate gratification preferences to academic success (Lessing, 1969), achievement motivation (Mischel, 1961a), social responsibility (Mischel, 1961 a, 1961c), and psychopathology (Unikel \& Blanchard, 1973) in that population. Moreover, certain theorists (e.g., Rainwater, 1970) have conjectured that such an "orientation toward immediate gratification (p. 230) is a result of a sense of impotence, unstable interpersonal relationships, and a disinclination to think about the future" (see also Pettigrew, 1964). A great deal of this line of theorizing is related directly to the empirical literature concerning father-absence (Mischel, 1958; 1961b), trust (Price-Williams \& Ramirez, 1974; Seagull, 1966; Strickland, 1972), locus of control (Strickland, 1972; Zytkoskee, Strickland, \& Watson, 1971), and conceptions of time (Mischel, 1961c).

Past reviews have devoted little critical attention to the body of evidence that relates to this fertile area of theorizing about Black populations (see Mischel, 1966; Renner, 1964). Consequently, much of what recent theorists have inferred from past research and conjectured regarding "a preference for smaller, immediate rewards" among Blacks (Mischel, 1966, p. 125), stands in marked contrast to the actual data. The accumulated evidence largely refutes rather than supports the construct validity of immediate gratification 
preference among Blacks. Accordingly, with minor exception the evidence fails even to substantiate that such preference characterizes the behavior of that population.

\section{Delayed Versus Immediate Gratification Preferences}

Systematic experimental research into delayed gratification began with Black subject populations in the Carribean (Mischel 1958, 1961c). Mischel had observed informally in the context of a village in Trinidad what earlier social observers had remarked upon in different settings (e.g., Drake \& Cayton, 1945). It appeared to Mischel and to his casual informants that a marked tendency obtained in Trinidadian Blacks toward immediate gratification (see Mischel, 1971). This seemed in striking contrast to the behavior of a native East Indian population that was characterized by self-deprivation and the postponement of gratification.

In an attempt to verify this cultural observation, Mischel devised a simple paradigm in which subjects were asked to make a choice between two alternative rewards for their participation in an experiment. Subjects could choose to receive a small reward to be presented immediately by the experimenter, or a larger, more valued reward to be presented somewhat later by the experimenter. In his initial investigation with 35 Black 7-to-9-year-olds (both sexes) and a comparative sample of 18 East Indians, Mischel (1958) offered the alternative of a one-cent candy immediately or a ten-cent candy after one week.

Sixty-seven percent of the Indian children selected the larger, delayed reward alternative; $33 \%$ chose the smaller, immediate reward. This pattern did, indeed, differ from that of the Black sample, who chose the larger, delayed alternative less often $(37 \%)$ than the smaller, immediate alternative $(63 \%)$. Neither of these patterns of choice in itself, however, could be characterized as preferential. In his sample of 18, Mischel's East Indian subjects would have needed to choose at a rate exceeding $70 \%$ to reject the null hypothesis of chance $(p=.05)$ selection of the large, delayed alternative (see Table 1). More germane to the present discussion, Blacks were equally nonpreferential in their selections, their $63 \%$ of choices for the small, immediate reward failing to exceed the rate required $(66 \%)$ at the $95 \%$ level of confidence by simple $z$-test.

In a somewhat later investigation Mischel (1961b) engaged 68 Black children from Trinidad and 69 Black children from Grenada, aged 8 to 9 years. These children were offered a choice similar to that of fered the earlier sample, a two-cent candy immediately or a ten-cent candy a week later. Fifty-three percent of the Trinidadian Black sample chose the two-cent candy; $47 \%$ chose the ten-cent alternative. This pattern conformed to chance. Of the Grenadian Blacks, only $24 \%$ chose the small, immediate alternative, whereas $76 \%$ clearly preferred the larger delayed reward at a rate that rejects the null hypothesis of 


\section{Table I}

Criterion Percentages for Significant*

Choice Behavior in Favor of Immediate or Delayed Reward

\begin{tabular}{cc}
\hline $\begin{array}{c}\text { Total number of subjects } \\
\text { making choices }\end{array}$ & Criterion \% \\
\hline 20 & 71 \\
30 & 67 \\
40 & 65 \\
50 & 64 \\
60 & 63 \\
70 & 62 \\
80 & 61 \\
90 & 60 \\
100 & 60 \\
125 & 59 \\
150 & 58 \\
200 & 57 \\
\hline
\end{tabular}

*Deviation from chance frequencies, significant at the .05 level.

chance, but in the direction of delay-preference.

Another sample of Trinidadian Blacks, this time ranging in age from 12 to 14, was engaged by Mischel (1961c) in a study of the relationship between immediate preferences and delinquency. Within the overall sample of 206 children, $68 \%$ selected a twenty-five-cent candy to be received in one week over a five-cent candy to be be received immediately $(32 \%)$. This pattern of clearly significant $(p=.05)$ preference for the larger delayed reward also obtained for that subsample of the overall group who were classified as nondelinquents. Nondelinquent children from a large elementary government school selected the twenty-five cent candy $74 \%$ of the time, clearly significant within that group of 136 . The delinquent subsample from a boy's industrial school selected the immediate reward $44 \%$ of the time, and the delayed reward $56 \%$, a pattern that did not depart from binomial chance.

This same pattern of inconsistent findings has been replicated in a range of variations on Mischel's initial paradigm. For instance, a sample of 112 Black Trinidadian 11-to-14-year-olds was presented with one actual reward choice and two hypothetical queries (Mischel, 1961a). Subjects could select either a ten-cent candy to be received immediately or a twenty-five-cent candy to be received in one week. In addition, they indicated either their agreement 
or disagreement with each of the following self-descriptive statements: "I would rather get ten dollars right now than have to wait a whole month and get thirty dollars then"'; "I would rather wait to get a much larger gift much later rather than get a smaller one now." On the basis of their three responses the children were assigned to consistent delay ( 3 delay responses), inconsistent delay ( 2 or 1 delay responses) and consistent immediate ( 0 delay responses) groups. Combining those who made two or three delay responses, $49 \%$ of the children can be said to have made delay choices. Using those who made either one or no delay responses, the combined nondelay (or immediate) groups totaled $51 \%$ of the overall sample. These rates of choice are obviously the same as chance. Even taking the consistent delay $(n=37)$ and the consistent immediat ( $n=30$ ) groups only, the dichotomy of choice would be $55 \%$ and $45 \%$, respectively. Although these frequencies are in the direction of preference for the larger, delayed reward, they do not depart from statistical chance for a sample of 67.

Strickland (1972) offered a different reward choice to 171 American Black children, aged 11 to 13 years. Following the completion of a questionnaire, the children were offered a choice between one $45-\mathrm{rpm}$ record immediately or three $45-\mathrm{rpm}$ records to be received in three weeks. Overall, $55 \%$ of the children selected the one record immediately, $45 \%$ selected to wait for the three records in three weeks. These frequencies again conform to chance, indicating nonpreference.

A series of four choices between small, immediate, and large, delayed rewards was presented to fourth-graders in a midwestern city. Hertzberger and Dweck (1978) asked 19 Black male and 15 Black female children to choose between one nickel immediately or three nickels in one week, two nickels immediately or five nickels in one week, two nickels immediately or three nickels in one week, a small candy bar immediately or a medium-sized candy bar in one week. Each child made all of these choices without knowing which of them would be the "real one" to determine the actual gift. Across the four choices, females selected the larger delayed alternative $53 \%, 47 \%, 53 \%$, and $54 \%$ of the time, respectively; males chose that alternative at rates of $63 \%$, $58 \%, 58 \%$, and $58 \%$ respectively. None of these was different from chance.

Price-Wiliams and Ramirez (1974) presented their sample of 60 Black fourth graders with these questions: "Suppose you could get $\$ 10$ now or wait a month and get $\$ 30$, which would you take?" "If you could get a small $5 \$$ can-

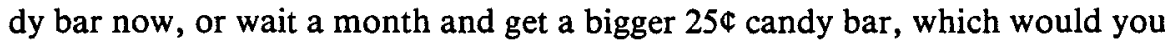
take?" "If you could get a small present now, or take a bigger one a month later, which would you take?" The first question was entirely hypothetical, whereas the latter two were accompanied by a tangible display of the alternatives and resulted in the child's actually receiving the chosen alternative. In response to the first query $18 \%$ of the children indicated a choice of the immediate $\$ 10$, while $82 \%$ indicated a choice of the $\$ 30$ to be obtained later. 
Thirty-three percent chose the smaller immediate candy bar, and $67 \%$ chose the larger, delayed one. Finally, $37 \%$ chose the smaller gift, and $67 \%$ chose to wait for a larger, more attractive alternative. All of these frequencies were, in fact, significantly different from chance and in the direction of delayed gratification preference.

Extending the strategy of presenting purely hypothetical verbal queries, Lessing (1969) devised seven items that related to choice situations (e.g., "If wearing ugly braces would make my teeth look prettier later on, I would put up with looking awful for a year or two"). Eighty-eight Black eighth- and eleventh-graders responded with either agreement or disagreement to each of the seven items and were scored zero or one for each immediate versus delayed response, respectively. The possible range of scores was 0 to 7 indicating from low to high delayed gratification preference, and the overall mean for the sample was 5.16. Using an estimate of the standard deviation of the scores, calculated from the reported analysis of variance results, would yield a $t$-value greater than 7.00 when the obtained mean is compared with a 3.50 scale midpoint. It can, therefore, be surmised that these Black subjects responded significantly in a delayed gratification direction.

In a somewhat ambiguous report of delayed gratification choices of 68 Black third-graders in Syracuse, New York, Seagull (1966) described two subsamples-one which was "unclassifiable" as to socioeconomic status, and one which was "classifiable." All children were offered a choice between one Hershey bar immediately and two Hershey bars to be obtained after waiting one week. Seagull reported that among the "unclassifiable" Blacks, $51 \%$ chose the immediate alternative, and $49 \%$ chose the delayed; these frequencies do not differ from chance. But among Seagull's "classifiable" group, $24 \%$ chose the immediate and $76 \%$ chose the delayed candy bars, indicating significant preference for the larger, albeit postponed reward.

Taken together these reports offer little substantiation of past impressionistic conjectures about the inability to delay gratification among Blacks. Clearly the majority of evidence reveals a pattern of nonpreference for either smaller immediate or larger delayed rewards within that population. At the same time, a considerable accumulation of evidence suggests quite the opposite of immediate preferences. Lessing, (1969), Mischel (1961b, 1961c), Price-Williams \& Ramirez (1974), and Seagull (1966) reported choice patterns among American, Trinidadian, and Grenadian Blacks that reflect a preference for delayed gratification. Against these findings only three studies within the experimental research literature support the notion that Blacks exhibit immediate reward preferences. Mischel (1958) found that his entire (albeit small) subsample of Black Trinidadian children who reported their fathers as not living at home $(n=10)$ chose the immediate reward alternative. Similarly, he reported in a later study, (Mischel, 1961b) that a subsample of "fatherabsent" Trinidadian Blacks $(n=23)$ preferred the immediate, smaller reward 
at a rate $(74 \%)$, which exceeded chance. Mischel interpreted both these observations in terms of trust, reasoning that the absence of a father may have undermined the confidence of these children in any promises made by authority figures. Strickland (1972) attempted to lend support to this thesis in a study of the effects of the promise-maker's race, and found that her sample of Black children $(n=84)$ preferred the immediate reward $(67 \%)$ in a white experimenter condition.

One possible interpretation of these overall results, therefore, may be that some Blacks do prefer immediate rewards some of the time, and that the aggregate trend of chance-like responding conceals a genuinely consistent response pattern in two distinct preference groups. Although the major burden of this argument in behalf of immediate preference in Blacks is borne by the discriminating construct of father absence (or trust), a broader body of validative research, speaks to this general line of reasoning. It may be appropriate, then, to turn to an analysis of that correspondent evidence before concluding our assessment of the status of delayed gratification in Blacks.

\section{Trust and Father-Absence}

In one of the very earliest experimental studies of delayed gratification Mahrer (1956) examined the hypothesis that acquired expectancies determine an individual's willingness to forego immediate rewards in favor of postponed alternatives. Accordingly, Mahrer presented lower socioeconomic children with experimentally manipulated experiences of fulfilled and unfulfilled promises of delayed reinforcements. On subsequent trials, those children subjected to expectancy disconfirmations chose the delayed rewards less often than children who had experienced confirmation of expected rewards. What is more, the effect of experimentally controlled trust was highly specific to the identity of the agent of past experience. That is, acquired expectancies were specific to the agent from whom they were learned; disconfirmed expectancies in the context of one agent did not affect later delayed reward choices in the context of a new agent.

Precisely what identifying characteristics of agents serve to establish the specificity or generality of acquired expectancies is not clear. In Mahrer's investigation, agents were all identical in race and sex, yet the specific experiential differences that distinguished them for subjects were sufficient to cue discriminant responding. Mischel (1958) conjectured that sex alone may be sufficient, however, to cue generalization of expectancies; and he hypothesized that a white American male might evoke distrust in children whose confidence in authority had been undermined by an absent Black father. Two experiments were directed at a test of this hypothesis.

In his investigation of Trinidadian Blacks and East Indians, Mischel (1958) asked children, "Does your father live at home with you?" Those who answered "no" were assigned to a "father-absent" group, comprised of ten 
such Black respondents and one East Indian. Although the sample of one East Indian did not permit inference, Mischel reported a unanimous tendency among "father-absent" Blacks to select an immediate reward, a trend that distinguished them significantly from "father-present" Black children. Moreover, with that investigation both father-absence and relative selection of overall immediate rewards distinguished the overall sample of Blacks from the overall sample of Indians, and Mischel reasoned that the resultant discouragement of trust among Blacks could explain the observed cultural-racial differences in behavior.

In a specific test of this hypothesis, Mischel (1961b) examined fatherabsence and delayed gratification in larger samples of Trinidadian Black, Grenadian Black, and Trinidadian East Indian children. The results were conclusively negative. Trinidadian Blacks differed significantly from Grenadians in their selection of delayed rewards, but the groups were undifferentiated in the incidence of father-absence. Neither did Grenadian Blacks differ from Trinidadian East Indians in the incidence of father-absence, though they differed significantly in preference for delayed rewards. Furthermore, in two separate replications with large samples of eleven-to-fourteen-year-old Trinidadian Blacks alone, no relationship obtained between father-absence and delayed- or immediate-reward preferences.

Pursuing a different line of reasoning, Strickland (1972) argued that within a given cultural context certain identifying characteristics of agents may cue expectancies in different directions. For American Blacks, white agents may be those for whom peculiarly negative expectancies have been acquired, the resultant distrust leading to an unwillingness to delay gratification in a choice situation. Her results confirmed this hypothesis by revealing a significantly greater proportion of Black children selecting delayed rewards offered by a Black experimenter as compared with a white experimenter. However, PriceWilliams and Ramirez (1974) found that spontaneous verbalizations of trust were more frequent in white than in Black children even though the race of the experimenter was matched to the race of the subjects.

It might seem that immediate reward preference among Blacks would derive from experiences primarily with powerful white social agents whose unfulfilled promises evoke distrust and uncertainty. This argument, of course, is quite distinct from that advanced by Mischel. It is also distinct from the body of evidence which reveals nonpreference and delayed-preference as predominant in Blacks.

Although specific experiences may have significant potential for shaping expectancies and resultant behaviors, Blacks may show a certain resilience which defies the generalization of effects. For example, Seagull (1966) reported that an experimental manipulation of trust, similar to that of Mahrer's (1956), significantly affected preferences for immediate and delayed rewards among Black third-graders. However, he also observed a recurring 
pattern of delaying behavior in "lower working class . . . Negro children who are overly trusting even in the face of repeated disconfirmation"' (p. 350), prompting him to conclude that "delay choice was a situationally determined variable," often defying "consistently broken promises" (p. 351) in that population.

\section{Social Responsibility}

Early experimental research also sought to establish the inability to delay gratification as a factor in social deviancy. Mischel (1961c) compared juvenile delinquents with controls from a population of Trinidadian Blacks. He reported that a significantly larger proportion of delinquents than of controls selected a five-cent candy to be received immediately. However, the proportion of juvenile delinquents choosing the smaller, immediate reward was actually smaller than the porportion choosing the larger, delayed alternative, although both proportions conformed to chance for that group. Furthermore, juvenile delinquents who chose the immediate reward were undifferentiated on Harris' (1957) measure of social responsibility from juvenile delinquents who chose the delayed reward. Finally, when reward choices were combined with verbal responses to two hypothetical queries, the resultant pattern of "delay" responses permitted the classification of "consistent delayers" and "consistent nondelayers." Only these extreme subgroups of the juvenile delinquent sample were different on the Harris measure.

In a similar investigation, Trinidadian lower and lower-middle class Black children were given one actual and two hypothetical choices between immediate and delayed rewards, and they responded to the Harris measure of social responsibility (Mischel, 1961a). Taken together, those children who gave 2 or 3 delay responses had higher social responsibility scores than those children who gave 1 or 0 delay responses.

Unikel and Blanchard (1973), however, failed to find any differences in delayed-reward choices between Black delinquents classified as psychopathic and those classified as nonpsychopathic. They also reported that Black psychopathics "manifested no significant difference in preference for delayed rewards as the delay interval increased" (p. 60). These findings are in direct contrast to Mischel's hypothesis that the time perspectives among juvenile delinquents affect delayed reward choices (1961c), or that social responsibility among Blacks is related to delay behavior.

\section{Achievement}

Early theorists argued that the ability to delay gratification is a critical factor in distinguishing those who persevere in hard work toward valuable longrange goals. Mischel (1961a) hypothesized that achievement motivation, as measured by fantasy expressions (McClelland, Atkinson, Clark, \& Lowell, 1953), is a central aspect of the personality of socioeconomically and 
academically successful persons, and that the construct validity of delayed reward choices should be reflected in a positive association between that behavior and $n$ Achievement. He predicted that individuals who are high in delayed reward preference would be those who "have learned to like work" (p. 544), and, in turn, are those who are high in $n$ achievement. In a sample of 112 Black Trinidadian eleven- to fourteen-year-olds this association did significantly obtain. The Pearson correlation between number of delayed reward choices (across three queries) and $n$ Achievement scores was .27 .

Whether, such association establishes the validity of delayed-reward choices as a construct implicated in actual academic and economic success is quite another matter. Considerable argument has been advanced against the ability of the $n$ Achievement measure itself to predict achievement outcomes for Blacks or distinguish them from other customarily successful populations in American society (e.g., Katz, 1967). In fact, a more direct test of the hypothesized relationship between delayed reward preference and achievement was carried out by Lessing (1969). That investigation measured delay preferences with seven hypothetical items reflecting choice situations (see p. 48). She correlated the resultant scores with the grade point averages for her combined Black and white eighth and eleventh grade samples, obtaining a Pearson coefficient of .23. However, she reported that the apparent influence of delayed gratification upon academic achievement "was solely by means of the variance shared with IQ"' (p. 160).

\section{Locus of Control and Acquiescence}

One final way in which past research has attempted to establish the construct validity of immediate gratification preference in Blacks is through its association with an individual's confidence in his ability to assert initiative and to control his reinforcement outcomes. Mischel (1961a), hypothesized that preference for immediate rewards would, therefore, be positively related to acquiescence in Blacks. Lessing (1969), Strickland (1972), and Zytkoskee, Strickland, and Watson (1971) hypothesized that such preferences would be positively related to an external locus of control, or a sense of powerlessness in Blacks.

Mischel asked his sample of Black Trinidadian youngsters to imagine that he (Mischel) was thinking of something with which they might agree or disagree. Without his indicating exactly what he was thinking, subjects were asked to indicate whether they believed they would agree (by indicating yes) or disagree (by indicating no). Those children who were high in delayed-reward choices more often indicated disagreement than children who were high in immediate reward choices. The validity of this measure of acquiescence, however, was unsubstantiated.

In a series of studies that employed a more generally validated measure, 
Strickland and her associates have found no association in Blacks between external locus of control and preference for immediate rewards. The locus of control scores in the Nowicki-Strickland (Note 1) 40-item instrument were virtually identical for Black eleven-to-thirteen-year-olds choosing immediate or choosing delayed rewards. Similarly, Zytkoskee, Strickland, and Watson (1971) found no correlation $(r=.09)$ between the Bialer Locus of Control Scale (Bialer, 1961) and their five-item measure of immediate- versus delayedreward preference in a sample of 76 Black ninth-graders. Furthermore, Lessing (1969) found that Blacks were significantly differentiated by a measure of locus of control, but they were not differentiated by a measure of delayed gratification preference.

\section{Conclusions}

In recent years, a rather explicit trend has emerged from the critical analysis of research into personality and social behavior in Blacks. Conventional paradigms, the constructs whose validity they were aimed at establishing, and the phenomena they are designed to reveal, appear to have benefitted from far more heuristic momentum than the empirical evidence would justify. The inability to delay gratification in Blacks can be counted among white-preference, external locus of control, and lack of motivation in this respect. Notwithstanding the characterization offered of Blacks in much of the published literature (Mischel, 1971; Pettigrew, 1964; Rainwater, 1970), experimental data largely represent Blacks either as preferring delayed gratification or as indifferent toward immediate versus delayed rewards. Five investigations (Herzberger \& Dweck, 1978; Mischel, 1958, 1961a; Strickland, 1972; Unikel \& Blanchard, 1973) show Black samples as either entirely or primarily nonpreferential toward the delay of gratification. Five (Lessing, 1969; Mischel, 1961 c, 1961b; Price-Williams \& Ramirez, 1974; Seagull, 1966) reveal either entire samples or subsamples of Blacks as preferring delayed rewards. In only three instances of published research (Mischel, 1958, 1961b; and Strickland, 1972) have relatively limited subsamples of Blacks displayed a preference for immediate rewards.

The meaning of such a trend is not immediately apparent. Taken together, the evidence may reflect a relatively consistent tendency among Blacks to distribute themselves normally around a central tendency of nonpreference for delayed gratification. On the face of it, such a trend could not reject the thesis that orientations among Blacks toward delayed gratification may underlie certain aspects of dysfunctional individual and social behavior. Going even further, it may be argued that the occasional selection by some Blacks of immediate reward alternatives is itself a behavior that differentiates those individuals from others, in the direction of dysfunctionality. In this sense the overall nonpreferential trends could conceal a theoretically meaningful dichotomy of preference among Blacks. 
These interpretations could be substantiated by a strong and consistent covergence of the construct validative evidence. On one hand, Blacks as a group might be characterized by a lack of motivation to achieve, by negative self-concept, low aspirations or a sense of powerlessness; but none of these generalized characterizations can be empirically substantiated. On the other hand, those Blacks who prefer immediate rewards may be peculiarly unsuccessful, irresponsible, socially untrusting, or subjectively powerless relative to other Blacks; the accumulated data scarcely sustain this hypothesis either.

Preference for immediate rewards has occasionally distinguished Black children of father-absent homes from those of father-present homes (Mischel, 1958). More often it has not (Mischel, 1961b). This failure of father-absence consistently to distinguish delayed gratification preferences might rest largely with its rough approximation to the more specific variable of trust. Yet theorists have never been clear about precisely what cues evoke trust in Blacks (cf. Price-Williams \& Ramirez, 1974; Strickland, 1972) or whether such sentiments, when aroused, play a significant role in the behavior of Blacks in the real world (Seagull, 1966). Mischel's findings suggested that the sex of a rewarding agent is sufficient to cue learned distrust; Strickland argued rather that the agent's race was the critical feature; and Price-Williams and Ramirez's results suggest that neither is necessary or sufficient. Seagull strongly argued that for those most likely to feel distrust, it might not matter anyway.

Although Blacks who prefer immediate rewards may be more acquiescent than others (Mischel, 1961 a), they do not perceive themselves as less capable of controlling their reinforcement outcomes (Strickland, 1972; Zytkoskee, Strickland, \& Watson, 1971). They may display less achievement in their fantasy expressions (Mischel, 1961a), but such expressions may not distinguish them from high achievers $(\mathrm{Kat} z, 1967)$ nor may such gratification preferences influence their actual success (Lessing, 1969). With respect to social responsibility, it is paradoxical that the same characteristic that distinguishes between normal and juvenile delinquent youngsters (Mischel, 1961c) fails to distinguish individual differences in either measured social responsibility attitudes (Mischel, 1961c) or psychopathology (Unikel \& Blanchard, 1973) within delinquent populations.

That the phenomenon of delayed gratification choices in Blacks has attained so equivocal a status is likely due to limitations in both its theoretical and methodological development. Early discussions reflected a status of theoretical indecision over the appropriate framework from which to approach the important questions. Mischel (1958), for example, appealed to such psychodynamic constructs as ego strength and such social learning constructs as expectancies, and to such antecedents as father-absence and time perspectives. But perhaps even more critical to the development of research in this area was the initial decision to proceed with a paradigm in which a sensitivity 
to reward latency was to be inferred from choices between alternatives that confounded that variable with reward quantity.

From the nature of choices made by subjects within the standard delayed gratification paradigm, it is impossible to distinguish preference for immediate alternatives from preference for small ones, or preference for delayed rewards from preference for large ones. A complete factorial design would, or course, have obviated this dilemma. Yet it was not explored. Quite apart from considerations of ego strength or expectancies, one might imagine that indifference toward the alternative rewards is fully to be expected. The net values of small, albeit immediate, and delayed, albeit large, rewards may, upon minor assumptions, be conjectured to be equal. Some recent research confirms this hypothesis (McQuater, 1980; Ward, 1976; Banks, McQuater, Pryor, \& Salter, Note 2) as well as its implications for choice behavior across the full range of delay and quantity permutations.

The most valuable aspect of the delayed gratification paradigm, in fact, may be its amenability to analyses of some of the most basic processes which govern the values of incentive stimuli for human behavior. In this regard, the predominance of nonpreferential responding in Blacks may serve as a logical point of departure for the analysis of the component features of incentive stimuli, and the rational manner in which their subjective significance bares upon motiviation and behavior. In that light, the limitations of past research findings for establishing the construct validity of delayed gratification seem possibly irrelevant. Far from disturbing, the status of nonpreference for delayed gratification in Blacks would potentially seem both coherent and heuristic for future research on reinforcement processes in Black behavior.

\section{Reference Notes}

1. Strickland, B. R., \& Nowicki, S. Behavioral correlates of the Novicki-Strickland locus of control for children. Paper presented at the meeting of the American Psychological Association, Washington, D.C., September, 1971.

2. Banks, W. C., McQuater, G. V., Pryor, J., \& Salter, B. The effect of reward amount, delay interval, and work on incentive value. Unpublished manuscript, 1976.

\section{References}

Bialer, I. Conceptualization of success and failure in mentally retarded and normal children. Journal of Personality, 1961, 29, 303-320.

Davis, A., \& Dollard, J. Children of bondage. Washington, D. C.: American Council on Education, 1940.

Drake, S., \& Cayton, H. R. Black metropolis. New York: Harcourt Brace, 1945.

Harris, D. B. A scale for measuring attitudes of social responsibility in children. Journal of Abnormal and Social Psychology, 1957, 55, 322-326.

Hertzberger, S. D., \& Dweck, C. S. Attraction and delay of gratification. Journal of Personality, 1978, 46(2), 215-227. 
$\mathrm{Katz}, \mathrm{I}$. The socialization of academic motivation in minority group children. In D. Levine (Ed.), Nebraska symposium on motivation. University of Nebraska Press, $1967,15,133-191$.

Lessing, E. Racial differences in indices of ego functioning relevant to academic achievement. The Journal of Genetic Psychology, 1969, 115, 153.

Mahrer, A. The role of expectancy in delayed reinforcement. Journal of Experimental Psychology, 1956, 52, 101-105.

McClelland, D. C., Atkinson, J. W., Clark, R. A., \& Lowell, E. L. The Achievement Motive. New York: Appleton-Century-Crofts, 1953.

McQuater, G. V. Delay of gratification: A theoretical and methodological address (Doctoral dissertation. Princeton University, 1980). Dissertation Abstracts International, Sept-Oct. 1980, 41-03, 1162B. (University Microfilms No. 80-1866-4)

Mischel, W. Preference for delayed reinforcement: An experimental study of a cultural observation. Journal of Abnormal Social Psychology, 1958, 56, 57-61.

Mischel, W. Delay of gratification, need for achievement, and acquiescence in another culture. Journal of Abnormal and Social Psychology, 1961, 63(3), 543-552, (a).

Mischel, W. Father-absence and delay of gratification. Cross-cultural comparisons. Journal of Abnormal and Social Psychology, 1961, 63(1), 116-124, (b).

Mischel, W. Preference for delayed reinforcement and social responsibility. Journal of Abnormal and Social Psychology, 1961, 62, 1-7, (c).

Mischel, W. Theory and research on the antecedents of self-imposed delay of reward. In B. A. Maher (Ed.) Progress in Experimental Personality Research, 3, New York: Academic Press, 1966.

Mischel, W. Introduction to personality. New York: Holt, Rinehart \& Winston, 1971.

Pettigrew, T.F. A profile of the Negro American, New York: Van Nostrand, 1964.

Price-Williams, D. R., \& Ramirez, M. Ethnic differences in delay of gratification. Journal of Social Psychology, 1974, 93, 23-30.

Rainwater, L. Behind ghetto walls: Black family life in a federal slum. Chicago: Aldine Publishing Company, 1970.

Renner, K. E. Delay of reinforcement: A historical review. Psychological Bulletin, $1964,61(5), 341-361$.

Seagull, A. A. Subpatterns of gratification choice within samples of Negro and white children. Papers of the Michigan Academy of Science, Arts, and Letters, 1966, 51(2), 345-351.

Schneider, L., \& Lysgaard, S. The deferred gratification pattern: A preliminary study. American Sociological Review, 1953, 18, 142-149.

Strickland, B. R. Delay of gratification as a function of race of the experimenter. Journal of Personality and Social Psychology, 1972, 22(1), 108-112.

Unikel, I. P. \& Blanchard, E. B. Psychopathy, race, and delay of gratification by adolescent delinquents. Journal of Nervous and Mental Disease, 1973, 156(1), $57-60$.

Ward, W. E. The use of internal-external locus of control and delay of gratification constructs in explaining Black behavior. Unpublished senior thesis, Princeton University, 1976.

Zytkoskee, A., Strickland, B. R., \& Watson, J. Delay of gratification and internal versus external control among adolescents of low socio-economic status. Development Psychology, 1971, 4(1, Pt. 1), 93-98. 